\title{
Miguel Torga y Gaziel: Mirada desde los polos de la península
}

\author{
Marcos Molina FernándeZ
}

Resumen: Estudio comparativo entre las obras Diarios del portugués Miguel Torga y Castilla adentro de Agustí Calvet, «Gaziel», focalizado en la mirada que ambos ofrecen de Castilla, y la relación de ésta con Portugal y Cataluña.

Palabras clave: Portugal. Cataluña. Literatura contemporánea comparada. Literatura de viajes. Miguel Torga, Diarios. Agustí Calvet, «Gaziel», La península inacabada (Castilla adentro).

Abstract: Comparative study between the works Diarios (Diaries), by the Portugues writer Miguel Torga and Castilla adentro (Castile inside) by Agustí Calvet, «Gaziel», fucused on the way in which they both represent Castilla, as well as it's relationship with Portugal and Cataluña (Catalonia).

Key words: Portugal. Cataluña (Catalonia). Comparative contemporary literature. Travel writing. Miguel Torga. Diarios (Diaries). Agustí Calvet, «Gaziel». La península inacabada (The unfinished peninsula).

\section{INTRODUCCIÓN}

La idea de trabajar con dos autores pertenecientes a dos extremos de la Península Ibérica me atrajo poderosamente desde el comienzo. Portugal y Cataluña, extremos, quizá, de una misma cosa. Los juegos del destino trajeron la independencia a uno, pero no al otro, habiendo sido tan afines en sus puntos de partida. Este deseo compartido de desprenderse de Castilla, regresando a su situación primera, quizá natural, quizá no - veremos todas estas cuestiones más adelante-, hizo que irremediablemente Cataluña y Portugal se miraran por encima de los desiertos áridos de Castilla, como expresa Fèlix Cucurull, en su volumen Dos pobles ibèrics (Portugal i Catalunya): 
Catalunya és un món llunyà. Es tracta d'una terra que només podia cridar l'atenció dels portuguesos del $1640^{1}$, perquè, aleshores, el futur de Portugal depenia, en grant part, del coratge dels catalans. A partir d'aleshores, els portuguesos no tenen perquè preocupar-se d'una gent perduda en la distància - uns de tants ciutadans de l'Estat veí. Tocant a aquest punt, però, Navarro i Monzó creu que van errats. Està convençut que és precisament als portuguesos que més pot beneficiar el coneixement de Catalunya. I escriu: «Si, per mal coneguts, els desigs i les aspiracions del poble català ni tant sols mediocrement exciten la sentimentalitat portuguesa, sempre ens queda l'esperança que la raó dels estudiosos s'interessarà per un problema suggestiu i que, encara que no sigui per altruisme, per propi interès, els homes de tots els partits que s'ocupen dels problems capitals de l'existència de Portugal com a nacionalitat independent no es negaran a acompanyar-nos en l'anàlisi de la qüestió catalana des del punt de vista de les relacions amb la sobirania de la nació lusitana (Cucurull 1967: 90).

Pero, además, encontraremos vínculos más allá de la política. Joan Maragall, poeta y pensador — sin que ambas cosas deban darse por separado—, expresará que

L'aire enrarit del desert central ha de fer que naturalment els dos vents de la mar s'hi precipitin i s'hi trobin, orejant tota la Península. Aquesta atracció, natural i benfactora, per damunt dels alts plans de Castella, sempre ha sigut presentida, i sols circumstàncies històriques, que avui semblen desaparèixer, han pogut contrariar-la (Cucurull 1967: 38).

Será esta cuestión la que me interesa: el encuentro entre el extremo oriental y el occidental en el centro de la Península, y su relación con Castilla, responsable a su vez de los destinos de ambos límites. Desde el comienzo encontré una particular seducción hacia la idea de trabajar con un escritor portugués y otro catalán, escritores, ambos, que llevan a cabo una profunda y larga mirada hacia Castilla. Ambos insertos en ella, y trayendo sus respectivos «vents de la mar», con que arrojarán su mirada fresca y luminosa a este «aire enrarit del desert central».

\subsection{Objetivos del presente estudio comparativo}

Mi objetivo será el de aproximar dos de las obras de estos autores: Castilla adentro, de Gaziel y Diarios de Miguel Torga, según sus títulos en castellano. Ambos son libros de viajes, en que se marcan itinerarios ${ }^{2}$, $y$ en que se describen

${ }^{1}$ Año de la Restauración de la Independencia Portuguesa, con el ascenso al trono del duque de Braganza bajo el título de Juan IV de Potugal (1640-1656).

2 Si bien en el caso de Torga será más difuso, pues, aunque está ordenado cronológicamente, no responde a itinerarios concretos, sino que guarda el carácter deslavazado del diario. No obstante, en él se recrea una suerte de itinerario «espiritual» — trayendo a colación a Dafoe y al término «biografía espiritual» con que bautizó a su Robinson Crusoe—, que va siguiendo el escritor portugués a lo largo de los años. 
tanto el viaje físico como la experiencia interna y personal de cada escritor. En sus descripciones tanto Torga como Gaziel ven más allá de lo visible, hablan acerca de la sustancia que reside bajo la apariencia de las cosas, ya sea geográfica, telúrica o antropológica. Hablarán de tales fondos tras haberlos experimentado en piel propia, tras haberse fundido con ellos. Y serán abundantes los casos en que trasciendan tal sustancia y reorienten la mirada hacia otros ámbitos, aparentemente inconexos con lo descrito, pero con vínculos soterrados que escapan a nuestra visión de adultos; cosas que ellos harán visibles. Así, de una simple misa en un pueblito perdido de la sierra, Gaziel nos hará una reflexión metafísica que nos dejará suspendidos; una metafísica que hila con los entresijos más hondos del funcionamiento de la Iglesia y del Estado. Por su parte, Torga, sólo comparando al pobre Gil Vicente con algún que otro literato español, echa a volar el poder de sus letras, y hace todo un manifiesto de satanismo gnóstico —en la línea de Milton o Goethe-.

Para establecer este vínculo entre ambos, trataré temas que en ellos se reiteran, o a los que les confieren una importancia singular. Existen temas de una gran relevancia, que deberé sortear en esta ocasión, siendo ya materia para futuros estudios, pues no establecen un claro vínculo entre los dos autores.

\subsection{Método empleado en el presente estudio}

Son muchos los textos seleccionados. Algunos de ellos de una considerable extensión. He intentado acortarlos, procurando no dilatar excesivamente el presente estudio comparativo, mas tal propósito se ha visto impedido en varias ocasiones ante la genialidad y cuerpo de ciertos extractos, que cuentan con una longitud considerable, y aunque trataré fundamentalmente de contenidos, mermar algunos de los textos seleccionados sería mermar su brillantez estilística, su progresión retórica. Así es que, en algunos casos, he preferido mantener el cuerpo que inicialmente consideré como el más adecuado.

El método consistirá en abrirme paso a través de una serie de temas que, como mencioné anteriormente, encuentro reiterantes o relevantes en ambas obras y escritores. Dentro de cada tema incidiré en la visión que ambos confieren al fondo tratado, aportando ejemplos — textos seleccionados de ambos autores-, evitando tomar yo la palabra; aunque en ocasiones aportaré mi particular visión, por lo común muy acorde con lo que ambos escritores nos van a ofrecer.

\section{CATALUÑA Y PORTUGAL: RELACIONES CON CASTILLA}

\subsection{La península inacabada}

He querido intitular este apartado haciéndome eco del gran trabajo de Gaziel, en el cual se ofrece una de las más hermosas miradas, humanas, geográficas y poéticas, de la Península que se hayan escrito. No obstante, antes de pasar a él, considero oportuno iniciar esta sección con las palabras preliminares que el mismo Torga escribe en su poemario Bichos: 
Lector de España, amigo:

«(...) soy un hijo occidental de la Iberia, y España ha sido siempre para mí un motivo de orgullo (...) Mi patria cívica acaba en Barca de Alva, pero mi patria telúrica sólo termina en los Pirineos. Llevo en mi pecho angustias que tienen necesidad de la aridez de Castilla, de la tenacidad vasca, de los perfumes de Levante y de la luz de la luna andaluza. Soy, por gracia de Dios, peninsular.» (Torga 41) ${ }^{3}$.

Ya en su inicio el escritor portugués llama al lector de España «amigo» (en la misma cita, posteriormente, se hará eco del carácter fraternal con que se siente unido al pueblo español). La distinción entre «patria cívica» y «patria telúrica», se relaciona con algo que comentamos anteriormente, en lo referente al tratamiento de «fondo humano» que llevan a cabo ambos escritores en sus descripciones y experiencias. Para ambos una patria será más humana que política, pero concederemos mayor atención a este tema en apartados posteriores.

Pasemos a Gaziel. La Península inacabada será el modo en que el escritor catalán se referirá al estado presente de la Península Ibérica. Un enunciado con cierta brillantez poética, que nos configura rápidamente la idea que nos transfiere: si las naciones se hacen, a lo largo de la historia, siguiendo una serie de patrones lógicos, bien sea la geografía - caso de los ríos, que tantas veces asumen el papel de frontera política y natural_- ¿por qué motivo no es Portugal parte del mismo Estado español? ¿Por qué Cataluña no dejó de serlo? Entendemos que las líneas limítrofes no son siempre asumidas por altibajos del relieve, ríos o montañas, sino por un belicismo regido por poderes superiores, tales como el Estado o la Religión (tantas veces la misma cosa).

La Península Ibérica es una de las realidades geográficas del extremo occidente europeo, dotadas de más acusado perfil. Soldada al continente tan sólo por la cadena pirenaica, parece estar casi a punto de soltarse de Europa, como si su instinto la indujese a distanciarse de ella (Gaziel 9) $)^{4}$.

Este tema es relevante: el distanciamiento de la Península respecto de Europa. Trataremos este tema más adelante. De momento nos interesa lo contemplado en esta cita referente a que, partiendo de una lógica geográfica, la Península Ibérica ofrecía unas condiciones adecuadas para haberse conformado como un estado único y unido. Dice Gaziel, en un fabuloso vuelo de su pluma:

Los cosmonautas que ya empiezan a surcar los espacios interplanetarios, pronto podrán físicamente verla en conjunto, como un bloque duro y compacto, erizado de cordilleras y orlado de espumas. Y si el viajero del aire procediese de

${ }^{3}$ Extraído de los Diarios de Torga, donde se incluye el prólogo a Bichos. Se encuentra en «Coimbra, 18 de mayo de 1944», (p. 41). Véase a partir de aquí ed. utilizada de acuerdo con Bibliografía final, Torga, Miguel.

${ }^{4}$ Véase a partir de aquí ed. utilizada de acuerdo con Bibliografía final, Calvet Pascual, «Gaziel», Agustí. 
algún astro lejano, al divisar por vez primera la bien recortada figura peninsular, a buen seguro que pensaría: «He aquí un territorio magnífico para formar una gran patria de esos seres humanos que pueblan la Tierra.» (Gaziel 9-10).

Esta misma cita continúa, y engarza con la idea de hermandad entre los pueblos íberos planteada por Torga en su prólogo a la edición española de Bichos (de la que hemos citado un breve fragmento). Torga expresará «¿Qué dirás tú, hermano del otro lado de la frontera (...)?». Y siguiendo con la última cita de Gaziel, encontramos:

Algo semejante sintieron, aunque en forma vaga y confusa, los propios peninsulares, desde los más remotos tiempos. Hay indicios ciertos de que en diversas ocasiones dieron pruebas de una hermandad rudimentaria (Gaziel 10).

Sin embargo, el transcurrir de los acontecimientos tenía reservado un destino distinto - lejos de toda hermandad - para estos pueblos íberos en plena formación:

Mas estos estados de ánimo - mera prehistoria del proceso integrador de una conciencia colectiva - no tomaron cuerpo hasta después de la invasión islámica que anegó la Península, a comienzos del siglo VIII de la era cristiana. La lucha religiosa contra el Islam, que los peninsulares practicaron por pequeños núcleos dispersos — cuyas entrañas contenían ya las semillas que más tarde serían árboles del nacionalismo medieval—, constituyó el factor determinante en la cristalización de un espíritu general hispano (Gaziel 10).

En esta última cita se trata el tema de la conformación del «espíritu hispano», que cobrará relevancia más adelante. Nos parece importante la cuestión de la invasión musulmana, y los siglos de Reconquista, como catalizadores de lo que hoy es la Península:

Para luchar contra el Islam, surgieron tres principales fuerzas reconquistadoras: uno al noroeste, otra central, al norte, y la tercera al noreste. Así surgieron tres Estados predominantes: Portugal, Castilla y Aragón. Los tres pelearon, juntos y por separado, por arrojar al invasor y, al propio tiempo, por engendrarse a sî mismos. Y pronto se produjo un fenómeno que con el tiempo cobraría decisiva importancia: Castilla les llevaba ventaja a los otros dos, no sólo en extensión territorial, sino también en ímpetu y alcance (Gaziel 10).

Así nos hallamos en uno de los enclaves que pretende conjugar este artículo: el predominio castellano como fuente de las tensiones políticas que se viven en la Península, y la evolución de dichas tensiones a lo largo de la historia. Gaziel, en esta introducción, nos expone la circunstancia primera:

Las fabulosas riquezas de América no se empleaban en beneficio de España ni de los españoles, sino en tratar de mantener en Europa la prepotencia de los Austrias extranjeros, quimera católico-imperialista que duró sólo unos lustros. Con todo ello quedó consagrada la hegemonía castellana dentro de un 
mutilado territorio peninsular, del que Portugal estaba ausente y en el cual Cataluña permanecía a regañadientes. (...) Así, lo que desde hace siglos llamamos España y Portugal, es sencillamente la Península inacabada, rota (Gaziel 12).

En este apunte queda resumido el destino que corrió la Península, y por el cual quedó disgregada y en constante tensión, como la Península inacabada, la Península rota, que hoy es. Pasemos ahora a hacer un recorrido a lo largo de las miradas que ambos autores nos ofrecen tanto de Portugal como de Cataluña.

\subsection{Portugal}

El primer rasgo de «rotura», usando la terminología de Gaziel, que observamos en la Península Ibérica, es la separación entre España y Portugal:

[...] Por vía de hábito y de costumbre, los peninsulares hemos llegado a considerar el destrozamiento de nuestra Península, ya consumado, no como un fenómeno que importaría corregir, sino más bien como un hecho fatal que debemos aceptar. (...) Ni la geografía, ni la etnografía, ni la economía, abonan esa torpe mutilación de un territorio. (...) La única explicación, ya que no justificación, de su existencia, es la de considerarla como la perpetuación de una incompatibilidad ancestral y misteriosa entre los dos pueblos, algo casi mitológico, rayano en odio ciego, como entre los atridas (Gaziel 12-13).

Cómo apuntábamos anteriormente, vemos cómo apenas podemos acudir a otra explicación más que a la existencia de una «incompatibilidad ancestral y misteriosa entre los dos pueblos», pues, parece que por lógica debiera haberse conformado un único país. Encontramos, no obstante, factores que han contribuido en que tal separación se haya producido y perpetuado, caso de la lengua y las variadas evoluciones de ésta en las distintas regiones de la Península; o las guerras europeas, donde Inglaterra, por ejemplo, participó en favor de la emancipación de Portugal; o las ideas nacionalistas que, aun en calidad de germen, existen desde la noche de los tiempos. Todas son causas que pudieron haber provocado ese «odio ciego» al que se refiere Gaziel.

Por su parte, Torga aludirá a la relación entre Portugal y España en ocasiones, pero no tantas como cabría esperarse. Sus alusiones irán orladas de un tinte oscuro, pesimista, casi guardando un rencor oculto hacia su propia tierra, la cual no termina de hacerlo sentir peninsular, anhelo que encontramos en el siguiente fragmento:

Évora, 14 de febrero de 1942. [...] No hay en este país [Portugal] ningún lugar, a excepción de Évora, que haya sido capaz de decirme por medio de la pureza y de la belleza que soy latino, que soy árabe, que soy cristiano, que soy peninsular, que soy portugués, que soy, en definitiva, esa trágica mezcla de sangre mística y pagana que hace de mí ese pobre hombre que ya sabemos (Torga 62). 
Torga llega incluso a recriminar a Portugal, en algunas ocasiones, su falta de grandeza, aquella grandeza que sí observa en el resto de España, y que no pareció tocar a su país; Torga parece quejarse, incluso, no solo de la carencia de esa energía vital, sino de no haber intentado siquiera hacerse con ella, como hiciera su vecina Castilla. Sus reflexiones, la mayor parte de las veces, a la luz y brillo de las letras españolas:

Coimbra, 1944 (Prólogo a la traducción en castellano de Bichos):

¿Qué dirás tú, hermano del otro lado de la frontera - tú que posees la gran lección de los bisontes de Altamira, del Rocinante de don Quijote y del Platero de ese soñador de hoy — qué dirás tú de estos familiares animales portugueses que carecen de historia, de hazañas, de artificios? (...) Parece un abismo de oposición irreductible lo que nos separa y, en el fondo, pintamos la misma verdad con matices diferentes (Torga 91).

Torga admira, casi venera, la literatura española, y ve la portuguesa como una tenue sombra desalmada de ésta. La literatura, como se aprecia en el pasaje completo, forma parte de la construcción de la sociedad, del país, incluso de las gentes y del modo que tienen de ver y entender su propio entorno, su propia geografía. En Portugal, según él, no parece acontecer así, pues dirá que son de «una naturaleza humana atenuada y sencilla». Y reduce la grandeza del Don Juan español, que ha dado la vuelta al mundo, a un simple gallinero en las playas portuguesas. Vemos otra frase que une a ambos autores con una línea casi recta y palpable: «Parece un abismo de oposición irreductible lo que nos separa y, en el fondo, pintamos la misma verdad con matices diferentes», lo cual nos trae inmediatamente a la cabeza aquello que decía Gaziel en cuanto a «la perpetuación de una incompatibilidad ancestral y misteriosa entre los dos pueblos, algo casi mitológico, rayano en odio ciego, como entre los atridas» (Gaziel 12-13). Uno alude a un «abismo de oposición irreductible», el otro a una «incompatibilidad ancestral y misteriosa»; vemos en el trasfondo de ambas citas la misma idea: no es posible explicar, entender en su plenitud, el motivo por el cual se hayan separado, y especialmente desvinculado, ambos países. Podemos contemplar cientos de motivos y razones, a la luz de la historia, a la luz de la lengua. Pero no el motivo real, el cual deja de lado el sentimiento de aquella «hermandad humana» en que ambos escritores confluyen. Es comprensible, aunque un hecho siempre atroz, que la Península haya guerreado contra otras regiones europeas y africanas, como de hecho hizo. Mas las guerras internas que contemplan los ojos de la historia, resultan en tantos parámetros inexplicables. No puedo más que sumarme al planteamiento de Torga y Gaziel, y entender que hay vacíos de comprensión, «abismos de oposición irreductibles», «incompatibilidades ancestrales y misteriosas», desde las que se construyó el mundo como hoy lo vemos.

\subsection{Cataluña}

Estaba escrito que, partiendo de los mismos principios de incomprensión en que se vio sumida Portugal, derroteros políticos e históricos, Cataluña se hubie- 
ra emancipado también del resto de la Península, al menos de Castilla, pues ambas regiones son de una naturaleza por completo diferente a la castellana. Esto es visible en ambos autores. Comencemos por los apuntes históricos que nos brinda Gaziel:

Cataluña es una prócer nación medieval, de origen carolingio y pirenaico cuyo espíritu no supo y no pudo nunca encarnarse en un Estado propio y exclusivo (Gaziel 15).

Continuará, más adelante, con aspectos que ponen en común este apunte histórico con la situación presente de Cataluña respecto de España y Portugal:

Lo que Cataluña debía haber hecho, cuando era tiempo, pero que no supo o no pudo hacer, como lo hicieron Portugal y Castilla, fue erigirse en Estado propio, exclusivo e independiente, a caballo sobre el Pirineo. Esta oportunidad le falló, y no hay que pensar más en ella. Le quedaban, no obstante, dos más, y las dos de primer orden: una, la de luchar una vez expulsada de Francia, por el predominio peninsular, como lo hizo Portugal sin conseguirlo, y también Castilla, hasta obtenerlo; y la otra, deslindarse enteramente, cuando menos, de lo castellano, tanto en el territorio como en el espíritu, al modo que lo realizó Portugal [...] es obvio que la primera culpable de la situación consiguiente es Cataluña misma. Eso de que Castilla y la España castellanizada sean responsables de todos nuestros males - de los que realmente nos vinieron de ellos y también de los que nosotros mismos, los catalanes, nos hicimos y nos seguimos haciendo-, a lo sumo puede ser un comodín de politiquilla local, que no ha ido, no va ni podrá ir nunca a ninguna parte (Gaziel 31).

Así es que recrimina a Cataluña, como hiciera Torga con Portugal, el no haber sido capaz de asumir la actitud bélica y potente que sí tuvo Castilla —en el caso de Torga, aunque Portugal sí consiguió su independencia, su recriminación está orientada hacia la actitud interna, casi espiritual, de su país respecto de España- Contemplamos, no obstante, que Cataluña encierra un espíritu distinto al de Castilla; que no supiera encauzar su historia es otra cuestión, pero la diferencia es manifiesta, y también la observamos en Torga:

Barcelona, 6 de septiembre de 1950 (...)

Esta gente, rica y práctica, no entiende a Castilla. Las luchas de la vieja hechicera no le interesan a nadie. Allá ella si se desgarra, si se devora, si se pulveriza. La abundancia terrena de la cornisa marítima no quiere saber nada de agonías metafísicas. A quien Barcelona ha entronizado, y de tal modo que me dan nauseas patrióticas, porque soy de los que contestan su gloria, no ha sido don Quijote, sino Colón, como símbolo de una fuerza centrífuga, comunicativa, cosmopolita. Trabajador y sensible, el hombre de aquí, cuando fabrica o proyecta cosas concretas, tiene poco que ver con la sombra espectral de un salmantino que lanza eternamente en el desierto de la meseta la semilla abstracta de su fe. 
Los une, a pesar de todo, la fatalidad de un matrimonio geográfico, desafortunado, pero indisoluble. La naturaleza, de vez en cuando, se equivoca. Mete dentro de la misma cáscara una castaña grande y otra pequeñita (Torga 155).

En esta cita se nos abren varios temas relevantes. Lo que nos interesa es ver cómo Torga trata el espíritu catalán y lo separa del castellano. Observamos que hace mención a la riqueza de Cataluña, que también contemplamos en Gaziel, así como desinteresada en los derroteros bélicos de su vecina Castilla. Y menciona una palabra que será fundamental en ambos autores, si no la palabra misma sí su eco, sus resonancias, su semántica: «metafísica». De momento contemplamos que en cuanto a lo metafísico, Cataluña mantiene también un espíritu de despreocupación con respecto a Castilla, que siempre fue envuelta por ese halo religioso. Y de nuevo su lazo con la literatura: Castilla es Don Quijote, territorio soñador que emprende cruzadas inútiles y arremete contra fantasmas; Cataluña es Colón, emprendedora, «comunicativa», «cosmopolita». Ésta última palabra no ha de sonar extraña al lector de hoy, pues Cataluña, y por metonimia inversa Barcelona, resuena hoy en todo el mundo, precisamente por su apertura y su cosmopolitismo; por su movimiento, frente al estatismo castellano.

Ambos autores mencionarán que Cataluña, a consecuencia de este espíritu abierto y liberal propio, fue colchón perfecto para las ideas o ideales de la República española:

Barcelona 2 de septiembre de 1950. Fue en el Levante donde se refugió la República española, y fue en esta Cataluña donde la democracia depositó su esperanza. Las huertas de Valencia, fecundas y conciliadoras, eran un bello símbolo de comunidad y de armonía: el espíritu emprendedor y práctico de Barcelona daba garantías seguras de solvencia social (Torga 154).

Gaziel, por su parte, escribe:

El republicanismo ha sido siempre en Cataluña, más que adhesión consciente a una determinada forma de gobierno, protesta instintiva contra la incapacidad o la hostilidad imperantes (Gaziel 28).

Y ambos hablarán de su fracaso, respecto de estas «esperanzas depositadas por la República»:

Pero triunfó la tiranía castellana. Torquemada, con su antorcha de paja reseca, redujo a cenizas la pacífica y soñada fraternidad. Con otra fuerza y con otra obstinación, el hombre del centro opuso un no rotundo a cualquier vida terrena que no fuese a sangre y fuego... O el cielo, o el infierno. O Dios, o el Diablo (Torga 154).

Gaziel recriminará, en parte, a la burguesía la falta de capacidad, organización o interés, para haber contribuido a un discurrir distinto de la historia: 
Aquí [en Cataluña] la burguesía no constituyó jamás un factor hegemónico de gobierno, siempre encuadrada y sumisa entre una clerecía formidable y una militancia prepotente» (Gaziel 29).

\subsection{Propuestas de cambio frente a la «noche peninsular»}

Ambos autores expondrán el estado «oscuro» en que se encuentra la Península. Ambos, no obstante, ofrecerán sus propuestas para un posible cambio; propuestas siempre basadas en la movilidad frente al estatismo que parece innato al pueblo íbero:

Mientras las circunstancias no cambien radicalmente, lo mas probable es que Portugal siga sin querer ni oír hablar de su posible integración en un superior conjunto ibérico; Cataluña continúe atormentada por su complejo de Cenicienta espiritual peninsular, y Castilla, con la mayor parte de las tierras castellanizadas, se mantenga impertérrita en que no hay en la Península, no ha habido ni puede haber otra construcción superior a la suya, y que todo es perfecto en el mejor de los mundos posibles (Gaziel 32).

La siguiente idea viene de Torga, y toca la cuestión de la «unidad» que sería necesaria para sufragar los problemas que anegan la Península:

España, tierra madura en espera de una gran transformación, tiene que rever su unidad. Ni cuerpo sin corazón, ni corazón sin cuerpo (Torga 154).

«Ni cuerpo sin corazón, ni corazón sin cuerpo», no podría tener resonancias más poéticas. Como ya hemos mencionado en alguna ocasión, tanto Torga como Gaziel hablan desde una profunda objetividad y comprensión del entorno, por lo que mantienen una sabia cautela. Torga no manifiesta, como haría cualquier otro pensador o político más exaltado, que la Península haya de unirse. Solo que ha de «rever su unidad». Es común que al pensar en «unidad» pensemos en la asimilación por parte del componente más fuerte de los componentes más débiles que participan de ella; una absorción que conlleva una pérdida, una pérdida cultural, social, idiomática. La unión desde el respeto a la diferencia, la encontramos en la siguiente cita de Torga:

Ambas [Cataluña y Castilla] tienen su camisa individual, pero ¡que importa eso! Integradas en una única realidad espacial, tendrán que realizar juntas sueños diferentes (Torga 155).

«Realizar juntas sueños diferentes», de nuevo el estilo poético propio del escritor portugués vuelve a hacer vibrar sus palabras con deslumbrante brillo. Su propuesta es clara: la unión de ambos pueblos, en cuanto a integración de fuerzas, mas no de intereses. Un único fundamento, ya mencionado: el respeto. Una justificación para dicha unión: «la realidad espacial». Sin embargo, parecemos insertos en el mismo remolino, el cual no nos deja ver cuán fácil sería. 
Todo por no salirnos del esquema que ha trazado esta sociedad para nosotros, el cual se nos implanta, en pecho y cabeza, desde nuestra más tierna infancia; un esquema que parte de un sólo condicionante: la mirada hacia sí, el egoísmo. Sólo si Juan Goytisolo fuera de obligada lectura en las escuelas de toda España, ya habría quien se daría cuenta del entramado en que nos hallamos ciegamente inmersos, como peces en mitad de un gran océano. La propuesta goytisoliana:

La yuxtaposición de planos históricos y étnicos de la gran urbe propicia desde luego la existencia y proliferación de colisiones espaciotemporales, fenómenos de hibridación y mezcla dinámica de discursos que representan a mis ojos el sello inequívoco de la modernidad. La pluralidad y convivencia de estilos, su contagio recíproco, el valor energético de la ósmosis descentran la mirada al visitante, aniquilan su visión homogénea de las cosas, relativizan y fraccionan sus primeras impresiones globales (Goytisolo 277).

En estas palabras del escritor catalán de expresión castellana, encontramos la idea de la fusión entre culturas, y el cada vez más inservible concepto de la «uniculturalidad». Torga y Gaziel aún no se enfrentan a este panorama, pero la propuesta de convivencia y colaboración desde la diferencia no deja de ser la misma.

Gaziel, en su caso, opina que la posibilidad de cambio, la apertura de las vías para solucionar los problemas, recae sobre Castilla. Es natural, en este juego histórico en que tres regiones distintas se unieron desde sus diferencias, en principio para combatir y expulsar a los árabes del territorio íbero, Portugal, Castilla y Aragón, finalmente fuera Castilla la que alcanzara la supremacía sobre las demás, como también vimos, y como tal, como cultura que se extendió en todas direcciones y que absorbió a las otras, como potencia preponderante, tendría la responsabilidad, y sobretodo el poder, para plantear cambios a los posibles problemas:

Con todo, yo tengo para mí - después de haber vivido y reflexionado mucho estos problemas- que es Castilla, con su área de influencia, y nadie más que ella, quien podría aún aportar la solución apetecible antes de que el mundo dé más vueltas y una de ellas, a lo mejor, nos la traiga (...); que la Península Ibérica no va a permanecer en su estructura actual, indefinidamente, hasta que nosotros, los fugaces mortales que hoy parecemos disponer de ella, le demos permiso para cambiar, es tan cierto como puede serlo el más riguroso cálculo de probabilidades (Gaziel 32-34).

Es un planteamiento interesante. De no tomarse las medidas oportunas ahora, el propio devenir de la historia, o incluso la propia naturaleza de las cosas, propiciará ese «cambio», el cual, quizá, no será finalmente del gusto de ninguno. Ese devenir de los acontecimientos, que como mencionábamos anteriormente a veces parece darse al margen de las intenciones humanas, fue lo que procuró esa absurda división entre España y Portugal.

Quisiera concluir este apartado con una última cita de Torga. Una cita, de nuevo, con reverberaciones metafísicas, pero interpretable también como una 
propuesta para alzar todos las miradas por encima de nuestros propios problemas, mirando a los demás, y así poderse unir desde la diferencia de cada cual, y caminar juntos y en estrecha colaboración:

Como hombre que soy de muchas erosiones y de muchos vendavales, me voy de aquí [Mallorca] apaciguado. Cuando nosotros, los mortales, alcancemos la percepción divina, tendremos en la tierra, también, dispuesto a recibirnos, nuestro Olimpo (Torga 155).

\section{CASTILLA}

\subsection{Madrid, lo capital: lo artificial}

La idea de artificiosidad arquitectónica, al hablar de Madrid, la veremos reflejada en ambos autores. Un artificio implantado, antinatural, símbolo seguro del cosmopolitismo y la modernidad que ha de perseguir una capital, especialmente cuando ésta no la tiene de por sí:

Madrid, 21 de abril de 1951. Cuando atravesamos España de una punta a otra, lo que más nos impresiona es comprobar que sus monumentos no participan del ambiente. Son igual que tumores monstruosos en un cuerpo que los repele. En Italia, tenemos la sensación de que las obras de arte prolongan y completan la naturaleza. Aquí parecen estar en contra de ella (Torga 167).

En Gaziel leemos la misma idea, aunque con matices diferentes:

Si no se estropean y la replantación continúa, estas afueras de Madrid — que en mi juventud eran uno de los paisajes de desolación urbana más aplastantes que he visto en el mundo, como el que aparece en las primeras trilogías de Pío Baroja- se convertirán pronto en zonas residenciales, verdes y luminosas, como si las hubiera tocado una varita mágica (Gaziel 42).

Parece no albergar el escritor catalán la misma visión oscura de su colega portugués. Bien que se trate de una ironía, que resulta posible, pero sí contemplamos presente la cuestión que nos interesa: la implantación de un entorno mediante la construcción artificial del mismo, lo cual constituye, para Gaziel, la construcción de un ambiente; idea que también encontramos reconsiderada en Juan M. Ribera:

Ambas ciudades [Madrid y Valencia] (...) y aunque condenadas por próceres y por muchos de sus habitantes a ser parques temáticos-superficies comercialescentro de compras (...) llegaron a tiempo, con anterioridad a la hecatombe, a transmitir sensorialmente sus perfiles. (...) Entendida la ciudad como ocupación humana del espacio mediante la construcción de volúmenes que fuerzan un horizonte, el sentido primordial cuya acción le resulta propicia es la vista. (Ribera 189). 
En la siguiente cita veremos a un Torga que vuelve a la misma idea, aunque en un tono más suavizado:

Madrid, 30 de agosto de 1950. En el centro de esta gran mortaja de rastrojos, en que cada aldea con su torre nos recuerda un cadáver alumbrado por un cirio, Madrid ha intentado resolver con cierta amenidad su vida de capital. Ha hecho venir buen agua de lejos, ha levantado hacia el cielo canterías profanas, y ha abierto sus brazos mundanos a toda la nación (Torga 153).

Pero Gaziel no opina que tal «imposición al medio» sea producto de la modernidad, sino una práctica iniciada ya, al parecer, siglos atrás:

Era mentira que Castilla hubiera de ser, fatalmente, sólo sequedad y aridez. Tanta literatura como se ha hecho sobre esta sequedad supuesta, radical e incurable, reposa sobre una idea falsa. (...) Los alrededores de Madrid podrían ser, si no un vergel, un conjunto de bosques encantadores, como los de Bruselas, por ejemplo. La llanura sin un árbol, sin una sombra, sin un riachuelo, el inmenso arrasamiento de la mayor parte de la tierra castellana, no son obra de la naturaleza. La hicieron así los hombres, probablemente los africanos que vivieron en ella tantos siglos (...) que (...) prefieren, sobre todo porque los llevan congénitos en el alma, el espejismo y la inmensidad del desierto, y su profunda indolencia (Gaziel 43).

\subsection{Estatismo y aislamiento. Vacío y soledad}

Tomaré, como principal ejemplo del estatismo castellano, la ciudad de Ávila, hacia la cual dirigen, ambos autores, una mirada singular y muy afín. Se produce una suerte de metáfora metonímica cuando hablan de Âvila, símbolo de la inmovilidad castellana. Comencemos por Torga, y esta breve reflexión acerca de ciertas arquitecturas abulenses:

Ávila, 29 de agosto de 1950. La piedra de estas murallas parece recién salida de las canteras. Convencida de su papel de impedir la vida a la más pequeña partícula del fascismo que está sitiando, ni siquiera se ha fijado en la erosión que ha pasado junto a ella. ¡Granito temporal poniendo cerco al granito intemporal! (Torga 152).

A pesar de su brevedad, sin duda se trata de un apunte nada ligero, cargado con materia que propicia la reflexión. Por de pronto trata de la intemporalidad de las murallas de Avila, de las que dice que parecen recién hechas. Habla, pues, de un estatismo no de ahora, sino que se remonta siglos atrás. Ni siquiera la erosión hace mella en su piedra. Aunque, dice, que la erosión «ha pasado junto a ella». Nos da la idea de que, en torno a la ciudad, el mundo sí está en movimiento, mas no un movimiento evolutivo, sino decadente. Vemos también una referencia y crítica al fascismo - no abundan en sus diarios, aunque sí en otras obras del mismo autor-; un modo de resistencia literaria, tan enrevesado y poético, que bien pudo traspasar la estrecha criba de la censura franquista. $\mathrm{Y}$ vemos como 
transmite la idea de que lo caduco se lo llevará el tiempo, por mucho que quiera trastocar lo permanente, lo cual permanecerá cuando lo caduco haya desaparecido. Lo caduco es el fascismo. Avila es lo permanente. Y en contraposición a lo perenne, a lo estático:

Sólo una esperanza en este terremoto: Toledo se está cayendo, pero, al menos, hay movimiento. Es peor Ávila que está petrificada (Torga 153).

Así es que nos plantea que la alternativa al estatismo es lo decadente, caso de Toledo - lo veremos también en Gaziel—, mas declara el autor portugués preferir lo decadente, pues al menos consta de movimiento. Ambos autores coinciden en que «movimiento», sea cual sea su dirección, resulta mejor que «estatismo». Pasando a Gaziel, haremos un breve recorrido a lo largo de algunos fragmentos, extractos de un corpus más extenso, en que describe al detalle su paso por la Ávila:

Entre Villacastín y Aldevieja entramos en la provincia de Ávila. Monótonamente, las ondulaciones del terreno se suceden. La subida no se hace sentir apenas, pero sí una misteriosa impresión de altura. Ni un pájaro solitario. Las rocas se van apoderando de los campos y ya son innumerables, como los rebaños inmóviles y petrificados (Gaziel 45).

Curioso que aparezca, en ambos autores, la palabra «petrificado», en ningún caso baladí.

Poco a poco, llevándonos los maletines, porque no ha salido a recibirnos ni un perro vagabundo, entramos en la ciudad. (...) Dentro de sus muros la población parece muerta. (...) Seguimos calles tortuosas, placitas desiertas. (...) Suenan toques de campanas, espaciados, lentos. No pasa un alma (Gaziel 46).

Asociadas a Ávila, y a la semántica próxima a lo estático, encontramos estas ideas de «soledad» y «vacío». Por supuesto, leídas ambas obras, no es difícil establecer una analogía metonímica con gran parte del territorio castellano. Aunque el autor catalán declarará abiertamente que el caso de Ávila es el más extremo en cuanto a este asunto:

Ávila es, probablemente, la más triste, la más deteriorada de las antiguas y famosas poblaciones castellanas. No puede compararse con Toledo, por la extraordinaria mezcolanza de los tres mundos que en ésta se juntaron -el cristianismo, el musulmán y el judío-, como en un entramado de razas y culturas, ni por su grandeza imperial. No tiene tampoco la elegancia señorial y teológica de Salamanca, dulce y renacentista. No es un museo esparcido a lo largo de los siglos, como Segovia. Es Castilla pura, monolítica, y nada más. Y con un cuerpo reducido a su más mínima expresión: la indispensable para que se sostenga un espíritu (Gaziel 47).

En esta cita encontramos temas diversos, que confluyen todos en la temática que nos hemos propuesto tratar en este apartado. En primer lugar, como men- 
cioné, la idea de que Ávila es el mejor exponente del deterioro castellano, de entre sus más «antiguas y famosas poblaciones». Introduce esta palabra, «deterioro», al contrario de Torga, que hablaba de «estatismo»; es Toledo la que se deteriora para Torga. Para Gaziel, por el contrario, Toledo es una ciudad en que aún vibra su grandeza pasada, y asocia esta grandeza a ese encuentro entre culturas que dio forma a nuestro país: el Cristianismo, el Islam y el Judaísmo. Gaziel hace explícito el efecto metonímico al que nos hemos referido anteriormente, al afirmar que Ávila es «Castilla pura, monolítica, y nada más», palabras que se engarzan por sí solas con las de Torga. Por último, contemplamos en la cita de Gaziel que Ávila se trata de un «cuerpo reducido a su más mínima expresión: la indispensable para que se sostenga un espíritu». Esta idea evoluciona líneas más alante, y Gaziel desproveerá a Âvila incluso de eso, de espíritu, de alma:

Es un mundo que jamás volverá, no solamente porque ha perdido el cuerpo (en realidad siempre tuvo poquísimo), sino, además, porque se le ha esfumado el alma, que era extraordinaria. Esto perdura, pero no sobrevive. Toda Ávila es una pura pieza de museo, buena tan sólo para los estudiosos, para los historiadores, para los arqueólogos y escritores sensibles, que se complacen evocando horas y tiempos pasados para siempre (Gaziel 49).

\section{MI VISIÓN O A MODO DE LECTURA CONJUNTA}

He descubierto a dos autores que me han atado a ellos para siempre. Son dos pensadores apacibles, contemplativos, que nos han legado una amplia visión tamizada por su reposada filosofía. Ellos no entendieron el mundo en su plenitud, nosotros nunca lo entenderemos, pero es el intento de entenderlo lo que mueve al auténtico filósofo. Gaziel y Torga no cesaron en su empeño por saber, movidos por la sana curiosidad del niño que quiere conocer el juguete por todos sus lados, por dentro, en la distancia, en la proximidad. El niño - traigo a colación a Rilke y sus Elegías del Duino - consigue entender el juguete sin cuestionárselo, sólo integrándose en él. Torga y Gaziel no miran desde el acomodo de sus hogares, hablando únicamente desde el conocimiento adquirido en sus bibliotecas - bibliotecas, he de pensar, amplias y bien surtidas- No, en la actitud sana que mueve al niño, con el deseo profundo de conocer las cosas, aún más, de integrarse en las cosas, Torga y Gaziel salen de su entorno y se funden con lo otro; se funden con el propio viaje. Ambos son errantes. Son viajeros. Y es el viaje, enfocado con la sabiduría que se merece, lejos de todo movimiento o interés turístico, un ancho canal para conocer; citando a Mirella Marota:

En su libro sobre la educación de los jóvenes Rousseau ${ }^{5}$ le explica a Émile que para alcanzar la madurez del conocimiento es necesario viajar, pero que del viaje no importan los dos puntos extremos, el de la partida y el del regreso, sino lo que hay en medio de ellos (Marota 199).

5 Véase Rousseau (1966: 539). 
En la concepción del profesor Javier del Prado también contemplamos la fusión entre el viaje y el conocer:

La elección del punto de llegada del viaje cultural suele estar ligado a las riquezas que nos ofrece la alteridad: $y$, en el hallazgo de estas riquezas, a la emergencia del otro como contrapunto a la emergencia del yo. Su objetivo, en vez de ser espiritual, como en la peregrinación, suele ser epistemológico (cuando está ligado al descubrimiento o a la ampliación de un conocimiento étnico) u ontológico (cuando está ligado al descubrimiento y a la invención del ser para el otro y en el otro) (Prado 20).

Habla Javier del Prado de la alteridad, y del proceso de visión y construcción del otro en el viaje. ¿Son acaso estos escritores inventores del Ser para el otro y en el Otro? En mi opinión van más allá. Cierto que vuelcan el entorno en su interior, pero también son capaces de volcarse a sí mismos en el entorno. Y aún más, como mencioné líneas atrás, sabrán salirse de sí para contemplar y entender los entresijos y misterios de este difícil mundo.

Castilla es su juguete, el cual quieren entender, con el cual se integran, hasta ser la misma sustancia. Y es entonces cuando pueden hablar, pueden transmitirnos habiendo trascendido el plano de ser sujeto, siendo ya el objeto desde el que hablan. Dirá la profesora Victoria Sánchez-Élez, refiriénfose a la mirada de Torga:

Las plazas y los pueblos españoles le parecen, en 1954, escenarios donde la verdad está más allá de lo que se presenta, donde el espectador se fija en pequeños pormenores, como en una fachada rota, en la biografía en la que aflora algún pormenor (...) La mirada que nos muestra el escritor en este discurrir por el espacio español es en realidad un viaje hacia el interior de sí mismo (Rocha 1977), en una introspección continua que desde la individualidad, traspasada a lo más general, que es Portugal y los portugueses para convertirse a la postre en universal (Alegre 10077:33; Colinas 2006:72) (Navas Sánchez-Élez, 198).

Palabras que transmiten la intención y actitud del escritor portugués, de mirar adentro y desde dentro, la imagen que se crea del mundo exterior; intención y actitud que hago extensible a Gaziel. En este juego de exteriores que se reflejan en interiores, ambos escritores serán capaces de salirse de sí hasta el punto de dejar de ser ellos mismos, y contemplar lo exterior con mayor cercanía y comprensión. Ambos sabrán jugar entre el adentro y el afuera. Sus confluencias serán constantes.

Estos escritores han ensanchado mi conocimiento, pero también mis deseos de conocer más, de contrastar, de integrarme y ser para entender, lejos de todo estudio mecánico y desalmado de las cosas. Y digo que me han atado de por vida, no sólo por esta actitud infantil —en el mejor de los sentidos de la palabra—, ni por su capacidad, en los difíciles tiempos en que viajaron y escribieron —en que tan fácil era dejarse llevar por una tendencia política o por la contraria-, de salirse de su propio fuero para describir el paisaje del humo ibérico con juicio, conocimiento y objetividad; no, no sólo por esto me ataron, sino que fue, desde las 
primeras líneas de cada cual, el sabor de sus lenguajes - y que el manido término «sabor» se aleje de todo tópico, y se encumbre como le es propio-. Esto me ha atado a ellos de por vida. Porque escribir así, con un estilo tan potente, tan brillante, y también tan adentrado en lo humano, no es cosa fácil. Para llegar a tal nivel, del que sé que fueron portadores Cortázar, Víctor Hugo, Shakespeare, Homero o Cervantes, es necesario haber viajado durante años y desde la niñez por el caudaloso mar de la literatura; y no sólo haber navegado por centenares, por millares de libros, sino haberlos integrado en el alma. El haberse convertido en ellos. Esto, tan pobremente estudiado por los estudiosos y teóricos de la literatura, es lo que hace a un escritor, y lo que lo diferencia de un «escribidor» —en palabras de Ángel García Galiano, profesor de Teoría de la Literatura y Literatura Comparada en la universidad Complutense de Madrid-, contraposición que encuentra su correlación en el mundo del arte, donde se diferencia al artista del artesano. Torga y Gaziel son escritores, y baste con esto.

\section{BIBLIOGRAFÍA}

Calvet Pascual «Gaziel», Agustí (1987): Castilla adentro. Enciclopèdia Catalana; ed. Alianza, Madrid.

Cucurull, Fèlix (1967) Dos pobles ibèrics (Portugal i Catalunya). Editorial Selecta. Barcelona: 1967.

PRAdo BiezMA, Javier del (2006): «Viajes con viático y sin viático». Eugenia Popeanga y Bárbara Fraticelli (coordinadoras), Revista de Filología Románica: La aventura de viajar y sus escrituras. Anejo IV. Universidad Complutense, Madrid.

Goytisolo, Juan (1997) El universo imaginado. Edición de José Miranda. Espasa Calpe, S.A., Madrid.

MAROTA, Mirella (2006): «El viaje como diálogo con el lector: la experiencia epistolar». Eugenia Popeanga y Bárbara Fraticelli (coordinadoras), Revista de Filología Románica: La aventura de viajar y sus escrituras. Anejo IV. Universidad Complutense, Madrid.

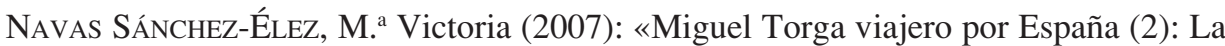
mirada portuguesa sobre las ciudades y pueblos españoles». Eugenia Popeanga, Pilar Andrade y Aurora Conde (coordinadoras), Revista de Filología Románica: Los sentidos sus escrituras. Anejo IV. Universidad Complutense, Madrid.

RiberA Llopis, Juan M. (2007): «Los sentidos en las ciudades de Alonso Zamora Vicente y de Vicent Andrés Estellés». Eugenia Popeanga, Pilar Andrade y Aurora Conde (coordinadoras), Revista de Filología Románica: Los sentidos sus escrituras. Anejo IV. Universidad Complutense, Madrid.

Rousseau, J.-J., Émile ou de l'éducation, París, Garnier Flammarion, (1966, p. 539). (Qtd. MAROTA, Mirilla (2006): «El viaje como diálogo con el lector: la experiencia epistolar». Eugenia Popeanga y Bárbara Fraticelli (coordinadoras), Revista de Filología Románica: La aventura de viajar y sus escrituras. Anejo IV. Universidad Complutense, Madrid)

Torga, Miguel (1988): Diarios (1932-1987). Selección, traducción, índices y notas de Eloísa Älvarez. Alfaguara. Madrid: 1988. 